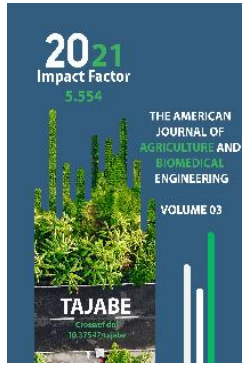

\title{
Biology Of Crocus Sativus L. In Termiz
}

\author{
Nazaralieva Mahfuza Pardaevna \\ Lecturer, Termiz Davlat University, Uzbekistan \\ Boboeva Nodira Tukhtamishovna \\ Independent Researcher, Termiz Davlat University, Uzbekistan
}

Journal Website:

http://theamericanjour nals.com/index.php/taj abe

Copyright: Original
content from this work
may be used under the
terms of the creative
commons attributes
4.0 licence.

ABSTRACT

This article observed the generative phase of the saffron plant grown in Termez conditions. Based on the data obtained, the daily and seasonal flowering dynamics of the plant were constructed.

\section{KEYWORDS}

Introduction, phenophases, seasonal flowering, daily flowering.

\section{INTRODUCTION}

Today, the problems of human health and its protection remain one of the most pressing issues in our country. In this regard, special attention is paid in our country to improve the production and cultivation of valuable plant raw materials that retain their beneficial properties for human health. Such promising plants include Crocus sativus L. - saffron. At present, the development of optimal methods of cultivation of Crocus sativus L. in the conditions of Termez, the organization of industrial plantations, the improvement of ways to produce quality raw materials are the scientific and practical importance. The study of the flowering stage during the vegetation of the introduced plants and the process that 
takes place at this stage allows them to be biologically and ecologically described or ecointroductive analysis $[3,4,5]$.

\section{LITERETURE VIEW}

The flower of the genus Crocus sativus is actinomorphic - straight, symmetrical, very beautiful bright purple, with elongated parallel black veins. The reverse ovate-edged or rounded part is bent, the two-leafed primary flower stalk is formed at the base of the nodule, which is covered by a long cylindrical tube of the corolla ( a part of a flower that has a Latin origin name little crown). The length of the tube of the corolla leaves depends on the planting depth of the bulb [2,7]. According to A. Askerov (1934), when the tubers were planted at a depth of 5 $\mathrm{cm}$ in the conditions of Apsheron, the curved part of the corolla leaves was $3.1 \mathrm{~cm}$ long and $1.6 \mathrm{~cm}$ wide, and the upground part of the corolla tube was $3 \mathrm{~cm}$. When the bulbs were planted at a depth of $15-20 \mathrm{~cm}$, the length of the corolla was much longer $(3.4 \mathrm{~cm}$ in length and $1.4 \mathrm{~cm}$ in width) and the length of the tube was $3.4 \mathrm{~cm}$. The total length of the corolla tube varies depending on the planting depth of the bulbs i.e. from $6 \mathrm{~cm}$ to $12 \mathrm{~cm}$. The number of pollinators is three, straight, opposite the outer side of the corolla. The powdery threads are white, loose at the top, and the bottom is joined by the corolla tube. The pollen grains are yellow, the main part is axillary, two-celled, longitudinally cracked. The seeds are 3-celled, separated from each other, the third part is funnel-shaped and $1.5-2 \mathrm{~cm}$ long [1]. The flowering phase is the most basic phase, which is a system that combines the interdependence of all phenophases and the adaptation of the plant to the new environment.

Due to the fact that our experiments were conducted in 2018-2020, and the generative phase was observed in our experiments in 2018-2019, we focused in detail on the indicators of daily and seasonal flowering dynamics of sown saffron plant in the first year. The object of study was the data on the duration of the flowering phase of the species C. sativus.

In 2018, the daily flowering dynamics of the C. sativus plant planted in Termez conditions were studied. The beginning of flowering (29.10.) At 8: 00-9: 00 in the morning the air temperature was $100 \mathrm{C}$, the relative humidity was $71 \%$, when the illumination was 10500 lux, 1 flower opened in 1 stem. From 10:00 to 13:00 the air temperature was $150 \mathrm{C}$, the humidity was $51 \%$, the illumination was $86000-90000$ lux, and 1 flower bloomed on 1 plant stem. From $14: 00$ to $18: 00$ no opening of flowers was observed in the plants. Thus, the opening of 2 flowers was observed for 1 day.

During the general flowering period (01.11.) The situation was as follows: at 8:00 a.m., when the air temperature was $10-120 C$, the relative humidity was $84 \%$, and the illumination level was 18,000 lux, 1 flower bloomed on 4 stems. From 9:00 to 12:00, when the air temperature was $130 \mathrm{C}$, relative humidity was $56 \%$, and the illumination was $45000-95000$ lux, 2 flowers bloomed on 3 stems. No opening of plant buds was observed from 13:00 to 18:00. During the total flowering period of the plant, the total number of flowers opened in 1 day was 10 . 




Daily flowering dynamics of Crocus sativus L. species

When we observed the final flowering period (11.11.2018), at 8:00 in the morning, 1 flower bloomed on 1 stem, at which time the air temperature was $17^{\circ} \mathrm{C}$, relative humidity was
$85 \%$, and illumination was 10,000 lux. During the remaining hours, no blooms were observed on the plant, and only 1 flower was found to bloom during the day.

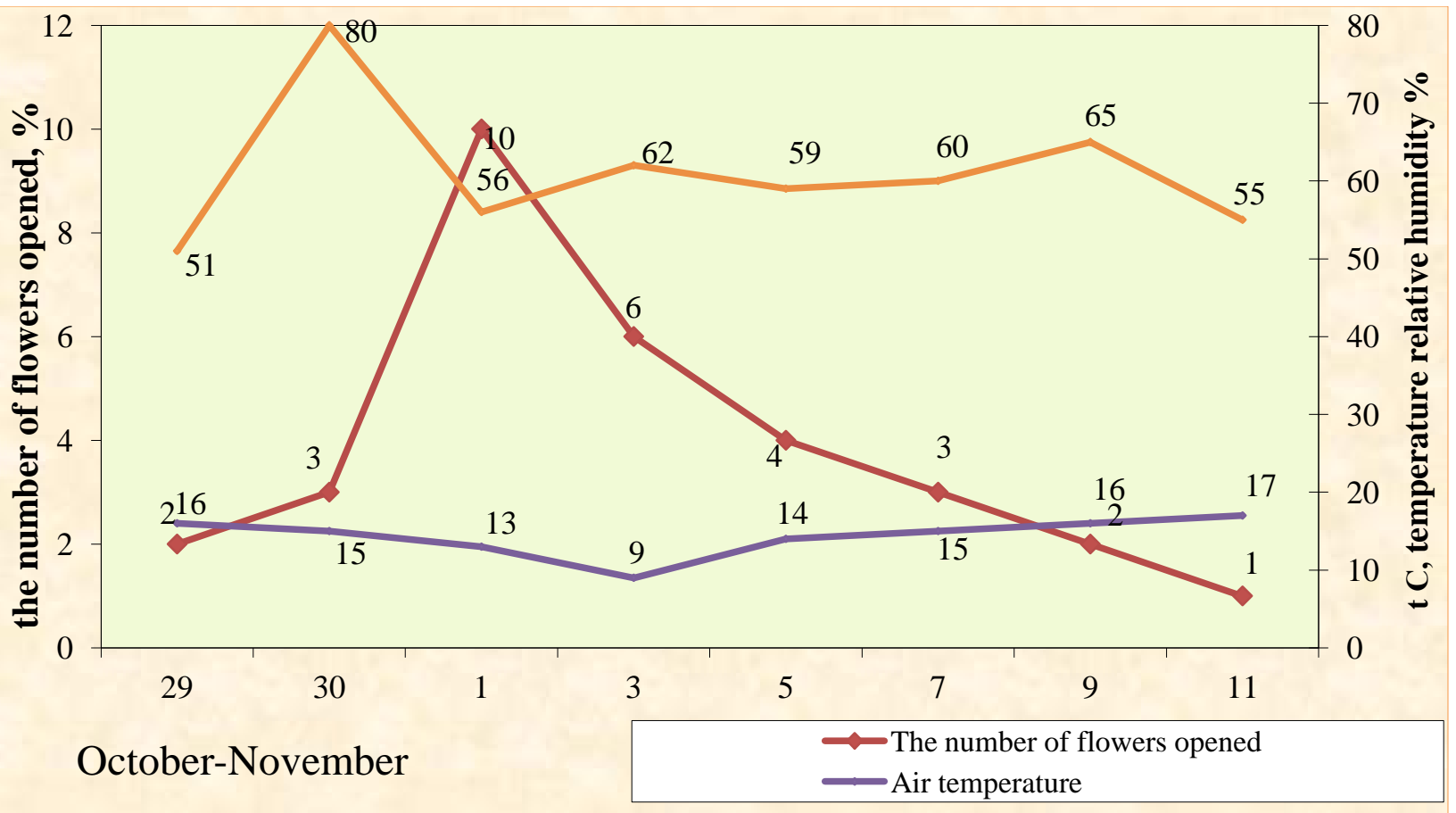

Seasonal flowering dynamics of Croc+-us sativus L. Species 


\section{CONCLUSION}

In conclusion, the fact that the plant has entered the generative phase from the first year, fully undergoes the process of flowering, shows that it is fully adapted to the conditions of introduction. This, in turn, indicates the possibility of growing and cultivating $S$. sativus in Termez. The virginil period of $C$. sativus lasted 8-9 months, the generative period lasted 12-14 days, and the total vegetation period lasted one season C. sativus - 215-220 days. The process of flowering in Termez depends on weather conditions, it was found that the decrease in air temperature, the increase in relative humidity, the average number of flowers opened. The maximum number of flowers opened during the day ranged from 8:00 to 11:00. At the same time, the air temperature for $\mathrm{C}$. sativus was $13-15^{\circ} \mathrm{C}$ and the relative humidity was $50-56 \%$.

C. sativus is a sterile plant that do not produce seeds, so tubers are used for propagation. Timing and rate of planting tubers, planting depth, row spacing, plant care, weeding, proper organization of agro-technological measures ensure high yields from the plant. $C$. sativus can be used for landscaping, given the fact that it blooms in autumn, the duration of flowering of a single flower is 4 days, high visibility during the period of generation and vegetation.

\section{REFERENCES}

1. Askerov A. Saffron. Azerneshr. Baku. 1934. 113 p.
2. Begmatov
A.M., Sattorov A.S. Bioecological properties of Stevia

rebaudiana Bertoni in introduction conditions. The American Journal of Agriculture and Boimedical Engineering. Volume 2 Issue 10, 2020. -R. 63-68.

3. Begmatov A. M., Rakmatova M.U. Bioecological properties of Helianthus tuberosus in introduction Conditions. The American Journal of Agriculture and Boimedical Engineering. Volume 2 Issue 11, 2020. -R. 82-85.

4. Mahmudov A.V. Introduction of some species of Crocus L. in different conditions. Tashkent, 2012. 7-40.

5. Jumaev X., Nazaralieva M. Some bioecological characteristics of crocus Sativus L. cultivation growing in Termez conditions International journal for Advanced research in Science \& Technology 17.07.2020. Pages 92-95. 